Seção Temática: Balanço do Fundeb

Volume 11 - $2021 \mid$ n. 12

\title{
Os efeitos do Fundeb na rede estadual de \\ ensino do Rio de Janeiro (2007-2020)
}

Fábio Araujo de Souza

Universidade Federal do Rio de Janeiro (UFRJ), Rio de Janeiro/RJ - Brasil

\section{Resumo}

Este artigo apresenta uma pesquisa que teve como objetivo analisar os efeitos do Fundeb na rede estadual de ensino do Rio de Janeiro no período de 2007 a 2020. Durante esse intervalo, o governo estadual destinou $\mathrm{R} \$ 62,6$ bilhões para a formação do Fundeb e recebeu, em contrapartida, apenas $\mathrm{R} \$ 30,2$ bilhões. A despeito dessa perda bilionária, a receita do Fundo cresceu no período analisado, embora o quantitativo de matrículas tenha reduzido drasticamente - em 2007, a rede de ensino atendia 1.189.781 educandos e, em 2020, passou para 670.950 , uma redução de $43,6 \%$. Ao mesmo tempo, os docentes com carga horária de 16, 22 e 40 horas amargaram uma perda salarial de $22 \%$, enquanto os de 30 horas, de $49 \%$. A lógica de capitalização da educação, o desenho institucional do Fundeb e as políticas educacionais gerencialistas são responsáveis pelos resultados da baixa qualidade da rede estadual de ensino.

Palavras-chave: Fundeb. Rede Estadual de Ensino do Rio de Janeiro. Seeduc.

\section{The effects of Fundeb on the state school system in Rio de Janeiro}

\section{(2007-2020)}

\section{Abstract}

This article presents a research that aimed to analyze the effects of Fundeb on the state school system in Rio de Janeiro in the period from 2007 to 2020. During this break, the state government allocated $\mathrm{R} \$ 62.6$ billion for the formation of Fundeb and received, in return, only $\mathrm{R} \$ 30.2$ billion. Despite this billion-dollar loss, the Fund's revenue grew over the period analyzed, although the number of enrollments has dropped dramatically - in 2007, the education network served 1,189,781 students and, in 2020, increased to 670,950, in a reduction of $43,6 \%$. At the same time, teachers with a workload of 16,22 and 40 hours experienced a wage loss of $22 \%$, while those of 30 hours, $49 \%$, during the Fundeb period. The capitalization logic of education, Fundeb's institutional design and managerialist educational policies are responsible for the poor-quality results of the state school system.

Keywords: Fundeb. Rio de Janeiro State Education Network. Seeduc. 
Os efeitos do Fundeb na rede estadual de ensino do Rio de Janeiro (2007-2020)

\section{Apresentação}

Segundo o artigo 212 da Constituição da República Federativa do Brasil de 1988 (CRFB/88), os estados devem aplicar $25 \%$, no mínimo, da sua receita de impostos e transferências na manutenção e desenvolvimento do ensino (MDE). A definição de tais despesas encontra-se no artigo 70 da Lei de Diretrizes e Bases da Educação Nacional (Lei federal 9.394/1996) e na Lei 7.348/85 (que considera inativos como despesa para MDE). Ademais, conforme o $\S 1^{\circ}$ do art. 212 da CRFB/88, a parcela de impostos transferida da União para os estados, Distrito Federal e municípios e de estados para municípios não é considerada receita do governo que a transferir.

O parágrafo $3^{\circ}$ do art. 212 determina que a distribuição dos recursos públicos deve assegurar prioridade ao atendimento das necessidades do ensino obrigatório, no que se refere à universalização, garantia de padrão de qualidade e equidade, nos termos do plano nacional de educação. O inciso I do art. 208 da CRFB/88, alterado pela Emenda Constitucional (EC) 59/2009, determina que o ensino obrigatório é dos 4 aos 17 anos de idade e aos que não tiveram acesso a ele na idade devida. Já o artigo 211 da CFRB/88, alterado pela EC 14/1996, determina que os estados devem atuar prioritariamente (não exclusivamente) no ensino fundamental e no ensino médio.

A rede estadual de educação básica do Rio de Janeiro, em 2019, atendia 788.767 educandos, em 2.541 estabelecimentos de ensino, onde atuam mais de 75 mil docentes. Por outro lado, o estado tem mais de 80 mil crianças e adolescentes fora da escola, e o número de pedidos de exoneração de docentes da rede estadual cresce a cada ano, sobretudo pelo baixo salário pago aos docentes. A violência e a desigualdade social também são fatores que desafiam as políticas sociais no estado, que tem o segundo maior Produto Interno Bruto (PIB), entre os estados brasileiros, ficando atrás somente de São Paulo.

Nesse sentido, é importante analisar os efeitos do Fundo de Manutenção e Desenvolvimento da Educação Básica e de Valorização dos Profissionais da Educação (Fundeb), principal política de financiamento da educação no País, que movimentou, em 2019, cerca de R\$170 bilhões. Só no estado do Rio de Janeiro, no mesmo ano, movimentou R $\$ 9$ bilhões, dos quais $R \$ 2,8$ foram para a rede estadual e $R \$ 6,2$ bilhões distribuídos entre os 92 governos municipais. De cunho quanti-qualitativo, este trabalho parte de um exaustivo estudo bibliográfico e documental acerca do financiamento da rede estadual de educação básica.

\section{Política de fundos na educação brasileira: a panaceia para os males do financiamento da educação?}

A política de fundos para financiar a educação pública, muito defendida atualmente, não é nova no cenário brasileiro. Na década de 1930, foi proposta pelos Pioneiros da Educação Nova como forma de viabilizar a autonomia econômica para a educação (AZEVEDO, 1932). Cabe ressaltar que a crise internacional de 1929 levou o governo brasileiro a adotar a sistemática planificação estatal nos domínios econômicos. O objetivo principal desse modelo foi a transição de uma economia eminentemente agrária para uma industrial. Nesse panorama político e econômico, foi criado o Ministério dos Negócios da Educação e da Saúde Pública, cujo objetivo era construir um sistema nacional de educação, sobretudo para formar mão de obra qualificada para o mercado (ARAUJO, 2011). 
Os efeitos do Fundeb na rede estadual de ensino do Rio de Janeiro (2007-2020)

Em 1932, através do Decreto 21.335, foi instituído o Fundo Especial de Educação e Saúde e seus recursos eram oriundos das taxas cobradas de documentos sujeitos a selo, de qualquer ente federativo (BRASIL, 1932) - sendo um terço do fundo reservado à educação (NUNES, 2017). A terceira Constituição do Brasil (1934), artigo 157, previa a criação de fundos de educação cuja fonte de receita deveria ser oriunda de uma parte dos patrimônios territoriais (BRASIL, 1934). Em 1942, foi prevista a criação, através do Decreto 4.958, do Fundo Nacional do Ensino Primário, proveniente dos tributos federais (BRASIL, 1942). A primeira Lei de Diretrizes e Bases da Educação Nacional (LDB) (Lei 4.024/1961) determinava que $12 \%$ dos impostos da União e $20 \%$ dos impostos estaduais e municipais, no mínimo, financiariam a manutenção e desenvolvimento do ensino. Além disso, essa lei previa a constituição do Fundo Nacional do Ensino Primário, do Fundo Nacional do Ensino Médio e do Fundo Nacional do Ensino Superior, nos quais nove décimos das receitas seriam recursos federais. Os fundos não foram implantados e, com a Lei 5.692/1971, foram suprimidos da LDB.

A política de fundos de educação foi retomada, em 1996, através da Emenda Constitucional 14 (EC/14), que, entre outras medidas, criou o Fundo de Manutenção e Desenvolvimento do Ensino Fundamental e de Valorização do Magistério (Fundef). O final da década de 1980 e a década de 1990 no Brasil foram marcados, por um lado, pelas conquistas sociais contidas no texto da CRFB/1988 e, por outro lado, pelo Consenso de Washington (1989), que foi propulsor das políticas econômicas neoliberais, sobretudo a partir de 1994, com a vitória de Fernando Henrique Cardoso na eleição à Presidência da República. Na área da educação, intensificou-se o processo de mercantilização através da adoção de políticas orientadas pelas instituições multilaterais internacionais. Segundo Leher (1999), a prioridade dada ao ensino fundamental "minimalista", principalmente através do Fundef, revelou o caráter do Estado brasileiro em atender a demanda da formação de trabalhadores pouco qualificados para o mercado de trabalho.

O texto original da CRFB/88, no artigo 60 dos Atos das Disposições Constitucionais Transitórias (ADCT), previa a aplicação de pelo menos $50 \%$ dos recursos mínimos vinculados à MDE, previstos no artigo 212, para eliminar o analfabetismo e universalizar o ensino fundamental (BRASIL, 1988); porém, essa subvinculação não foi cumprida. Em 1996, com a promulgação da $\mathrm{EC} / 14$, a prioridade ao ensino fundamental e à erradicação do analfabetismo se materializou sendo determinada a aplicação, por estados, Distrito Federal e municípios, de $60 \%$ dos recursos previstos no artigo 212 no ensino fundamental. É importante destacar que a EC 14/96, além de criar o Fundef, limitou os direitos previstos na CFRB/88 relacionados à obrigatoriedade do ensino fundamental para os maiores de 14 anos e à progressiva extensão dessa exigência para o ensino médio, uma vez que subvinculou parte considerável dos recursos, destinados constitucionalmente ao ensino, exclusivamente para o ensino fundamental, deixando de fora o ensino de jovens e adultos (PINTO, 2002).

A Lei 9.424/96 regulamentou e determinou que o Fundef seria de âmbito estadual e de natureza contábil, formado por $15 \%$ de alguns impostos estaduais, distritais e algumas transferências de impostos federais para estados, DF e municípios. A redistribuição dos recursos para estados, DF e municípios tinha como base o montante que forma o Fundo no âmbito de cada estado e o número de alunos matriculados no ensino fundamental regular presencial nas redes de ensino. A lei previa ainda a complementação da União aos fundos que não alcançassem o valor mínimo por aluno/ano definido pelo governo federal, bem como 
Os efeitos do Fundeb na rede estadual de ensino do Rio de Janeiro (2007-2020)

determinava que o controle e o acompanhamento social seriam realizados através de conselhos instituídos para esse fim (BRASIL, 1996b).

Como o Fundef tinha prazo determinado para vigorar (01/01/1997 até 31/12/2006), as discussões acerca de um novo fundo ganharam espaço no governo federal e nos subnacionais. Em 2005, o governo encaminhou ao Congresso a Proposta de Emenda à Constituição (PEC) 415, que, entre outras medidas, criava o Fundeb. Contudo, a PEC do governo continha várias limitações em relação ao novo fundo, como, por exemplo, a exclusão dos alunos da creche para fins de recebimento de recursos (BRASIL, 2005). Durante sua tramitação, o projeto sofreu diversas modificações e foi transformado em Emenda Constitucional, tornando-se a EC 53/06. É importante ressaltar o caráter pouco, ou nada, democrático de construção das propostas que originaram o Fundef e o Fundeb, pois ambas foram apresentadas ao Congresso Nacional pelo Poder Executivo sem quaisquer discussões preliminares com a sociedade e com os governantes dos demais entes federados, o que refletiu, por exemplo, na imposição do governo federal na forma de definir o valor aluno/ano desses fundos. Contudo, a tramitação das propostas foi intensamente discutida no Congresso Nacional, sobretudo pelos representantes da oposição, de representantes da sociedade civil organizada, das universidades públicas e demais instituições defensoras da educação pública, o que permitiu avanços significativos nos textos finais.

De âmbito estadual e distrital, o Fundeb tem natureza contábil, ou seja, sem personalidade jurídica, e período de vigência determinado em lei (2007-2020). Os fundos são constituídos por $20 \%$ de todos os impostos estaduais e de transferências estaduais e municipais, pela Dívida Ativa dos Impostos (DAl), multas e juros dos impostos e da DAI. A distribuição dos recursos se dá entre cada estado e seus municípios, proporcionalmente ao número de alunos das diversas etapas e modalidades da educação básica presencial, matriculados nas respectivas redes e nos âmbitos de atuação prioritária. A distribuição leva em consideração os fatores de ponderação de cada tipo de matrícula na educação básica (BRASIL, 2006). Para cada estado é calculado um valor por aluno/ano que não pode ser inferior ao Valor Mínimo Nacional Aluno/Ano calculado pelo MEC e pelo Ministério da Fazenda.

A complementação da União, depois dos dois primeiros anos de vigência, em que a implementação do fundo foi gradual, é de $10 \%$ do total dos recursos arrecadados para os fundos estaduais que não alcançam o valor mínimo aluno/ano nacional. A aplicação dos recursos dos fundos pelos entes deve ser de, no mínimo, 60\% para pagamento dos profissionais do magistério da educação básica em efetivo exercício e, os recursos restantes, devem ser aplicados em despesas determinadas pelo art. 70 da LDB. A Lei 11.494/07, que regulamenta o Fundeb, prevê ainda que o controle e o acompanhamento social dos recursos devem ser realizados por conselho criado por lei para esse fim (BRASIL, 2007).

O Fundeb, bem como o Fundef, trouxe poucos recursos novos para as redes de ensino estaduais, distrital e municipais. Sua lógica apenas redistribui recursos entre estado e suas prefeituras. Com isso, os governos que perderam/perdem recursos têm limitada sua possibilidade de manter e desenvolver sua rede de ensino. Além dos recursos da complementação federal, há os rendimentos financeiros auferidos pela aplicação dos recursos do Fundo e que não devem ser contabilizados dentro do percentual mínimo, mas sim adicionalmente a ele, pois não tem origem em impostos, e sim no rendimento financeiro 
Os efeitos do Fundeb na rede estadual de ensino do Rio de Janeiro (2007-2020)

destes. Muitos governos, durante diversos exercícios financeiros, omitiram/omitem esses rendimentos.

A complementação federal se limita apenas a $10 \%$ do total dos Fundos, embora o governo federal seja o ente que mais arrecada tributos no País (mais de $50 \%$ da arrecadação líquida), o que demonstra o caráter centrípeto do nosso federalismo. A Lei do Fundeb permite que parte dos recursos seja aplicado em creches e pré-escolas e instituições de educação especial confessionais, filantrópicas e comunitárias sem "fins lucrativos" conveniadas com o governo. Somente na creche privada conveniada o País tem mais de 560 mil matrículas (BRASIL, 2020). Esse privatismo comprova o descompromisso do Poder Público em financiar a criação e a expansão da educação infantil pública.

Outra limitação do Fundeb é que ele não é composto por toda a receita de impostos previstas para a MDE, deixando de fora os impostos municipais, o imposto de renda municipal e estadual e os $5 \%$ que não contabilizam para o Fundo. O efeito disso é que muitos governos não aplicam esses recursos na educação básica, sequer na área de atuação prioritária. No caso dos estados, muitos aplicam esses recursos no ensino superior (que muitas vezes engloba os hospitais universitários) e nas agências de fomento à pesquisa (que não financiam exclusivamente pesquisas da área da educação). O governo estadual do Rio de Janeiro, segundo constatou a equipe técnica do Tribunal de Contas do Estado do Rio de Janeiro (TCERJ), em 2012, aplicou recursos da MDE nas universidades estaduais e na fundação de amparo à pesquisa. Na mesma proporção, esses recursos deixaram/deixam de financiar a educação básica e esse descompromisso tem sido notado, sobretudo, pelo fato de o governo estadual, até a presente data, não ter aprovado seu Plano Estadual de Educação, que tinha, como período limite para aprovação, 25 de junho de 2016, segundo o artigo $9^{\circ}$ da Lei federal n. 13.005 de 2014 (RIO DE JANEIRO; TCE-RJ, 2012).

É possível constatar que, em todas as redes estaduais, com exceção do Acre, e em diversas redes municipais, o número de matrículas diminuiu no período de 2007 a 2017, o que demonstra que o Fundeb não desenvolveu as redes de ensino, como propagandeado pelo próprio governo federal, e tampouco universalizou a educação básica, como previsto nos Planos Nacionais de Educação. Segundo, Davies (2019, p. 671), "O número de matrículas estaduais e municipais diminuiu, respectivamente, $5.704 .486(-26 \%)$ e $1.429 .275(-5,8 \%)$, sendo que o de matrículas privadas cresceu 1.540 .858 (+21\%)". Por fim, o acompanhamento e o controle social dos recursos do Fundeb, através de conselho criado para esse fim, demonstram que há enormes desafios a serem superados, pois a maioria das pesquisas científicas publicadas sobre o tema constata a limitação imposta do agir de muitos conselheiros, endossado pela burocracia tendenciosa dos governantes; a falta de formação específica sobre o tema; a falta de transparência dos governos; a imparcialidade de certos conselheiros com a administração pública, por conta dos cargos que ocupam, entre outros motivos que inviabilizam um acompanhamento e controle social eficazes (CALEGARI, 2017).

O desenho institucional do Fundeb avançou em diversos aspectos em relação ao Fundef, entre eles destacam-se: abranger todas as etapas e diversas modalidades da educação básica, regras para a complementação federal aos Fundos, definição de parâmetros para a constituição dos conselhos do Fundo; avaliação periódica; cômputo das matrículas tendo como critério as áreas de atuação prioritária; abrangência de mais impostos e transferências para a composição do Fundo e o aumento do percentual de impostos e 
Os efeitos do Fundeb na rede estadual de ensino do Rio de Janeiro (2007-2020)

transferências para sua composição (SENA, 2008). Contudo, suas limitações devem ser enfrentadas na busca de uma política de financiamento da educação básica que de fato desenvolva e mantenha com qualidade as redes de ensino do País, que devem alcançar a totalidade de crianças, adolescentes, adultos e idosos, que estão à margem do direito constitucional à educação.

\section{Os efeitos do Fundeb na rede de ensino do estado do Rio de Janeiro (2007 a 2020)}

O Gráfico I apresenta a Receita Líquida de Impostos e Transferências Constitucionais (RLIT) do estado do RJ e as despesas em MDE, em valores nominais, dos exercícios financeiros de 2007 a 2020. Os valores, da maioria dos exercícios financeiros, foram retirados dos relatórios das prestações de contas elaborados pela equipe técnica do TCE-RJ, exceto os de 2008 e 2020, consultados no Sistema de Informações sobre Orçamentos Públicos em Educação (Siope) do Fundo Nacional de Desenvolvimento da Educação (FNDE), órgão vinculado ao Ministério da Educação (MEC) e na Lei Orçamentária Anual (LOA) (Lei estadual 8.731, 24/01/2020), pois os relatórios do TCE-RJ não estavam disponíveis no site nesses períodos. Privilegiaram-se os dados do TCE-RJ, por serem mais próximos do real, uma vez que são analisados pela equipe técnica do Tribunal a partir de documentos detalhados que compõem a prestação de contas. Os dados do Siope/FNDE são alimentados pelo Relatório Resumido de Execução Orçamentária (RREO), preenchido pelo próprio governo e com poucos detalhamentos além de algumas divergências em relação aos dados do TCE-RJ. Os dados de 2020 foram retirados da LOA, portanto, tais valores são estimados.

Em relação ao cálculo das receitas, uma irregularidade apontada pelo TCE-RJ é de não contabilizar na RLIT o percentual de $2 \%$ que compõe o Fundo de Combate à Pobreza previsto no ADCT, art. $82, \S 1^{\circ}$ da CRFB/88. Segundo a Secretaria do Tesouro Nacional (STN), a dedução só pode ocorrer quando forem deduzidos os percentuais para MDE. Outra irregularidade é que, em muitos exercícios financeiros, não foram contabilizados na RLIT as multas e os juros de mora em decorrência de atrasos no pagamento do imposto, o recebimento de impostos em atraso que foram anteriormente inscritos em dívida ativa e suas multas e juros de mora. Outra irregularidade tem relação com o Fundo de Administração Fazendária (FAF), que é composto por $1,05 \%$ do ICMS e $70 \%$ das multas, entre outros. Embora a lei que regulamenta o Fundo determine que o percentual do ICMS seja calculado depois da dedução do percentual do Fundeb, o percentual das multas não explicita isso; por consequência, as multas sofrem a dedução do FAF, para depois ser calculada a dedução para o Fundeb, resultando em perdas de receitas - provavelmente isso também ocorre com o cálculo da RLIT. 
Os efeitos do Fundeb na rede estadual de ensino do Rio de Janeiro (2007-2020)

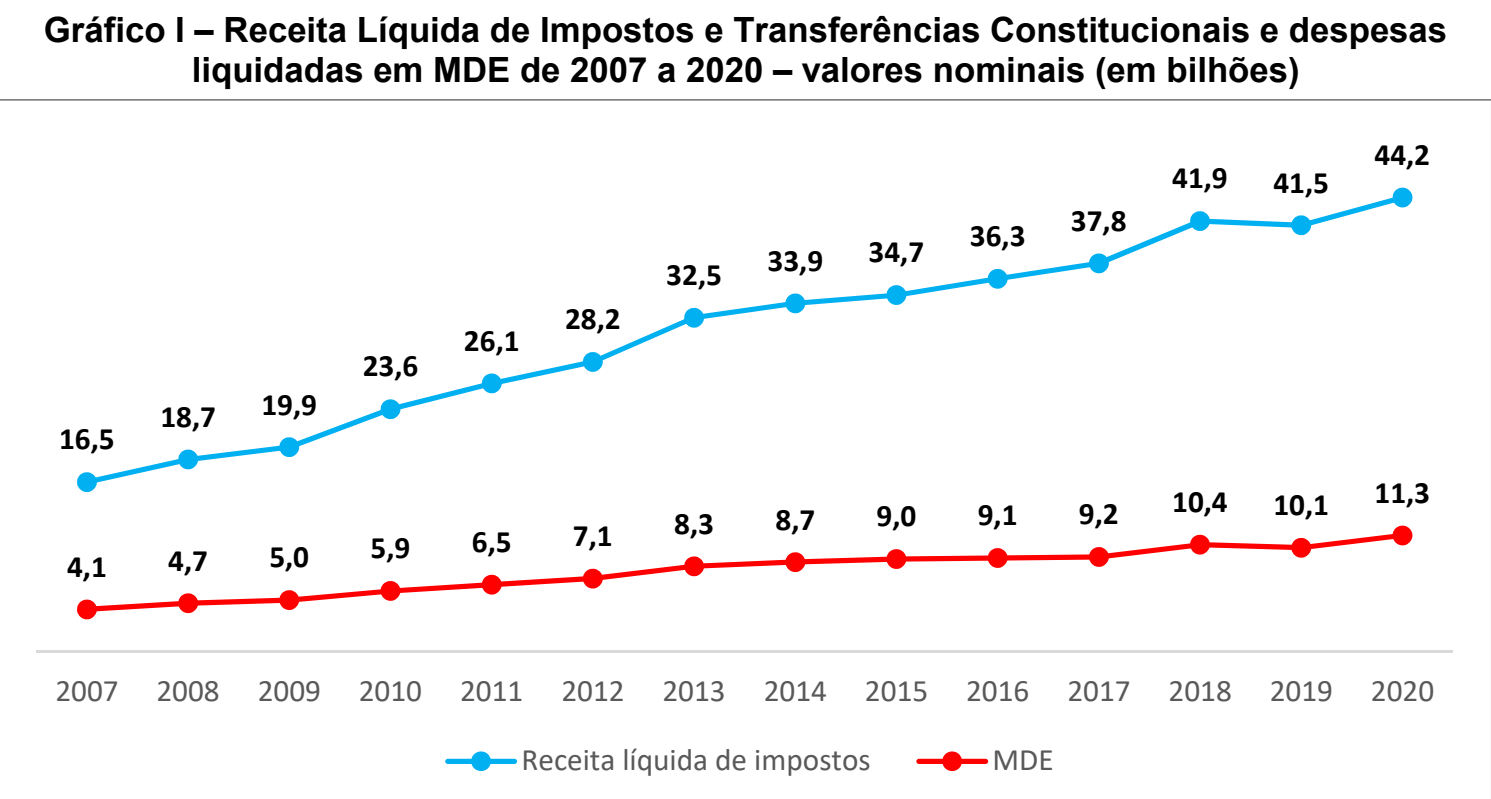

Fonte: Gráfico elaborado pelo autor com base nos dados de TCE-RJ, LOA 2020 e Siope/FNDE-MEC.

A sonegação, a elisão e a evasão fiscais, bem como o benefício fiscal (isenção, redução e renúncia), combinados com generosas linhas de crédito subsidiado cedidas às empresas fluminenses também diminuem a RLIT e, consequentemente, a receita para o cálculo do percentual mínimo do ensino. Seria contraditório o fato de o estado do RJ conceder tantos benefícios e mesmo assim ter tido quase sempre crescimento de arrecadação tributária, conforme o Gráfico I aponta. No entanto, a contrapartida (exigida por lei, para tentar manter o equilíbrio e a força arrecadatória) é o aumento de alíquota para outras empresas, para outros produtos, ou para outros ramos de atividade. Assim, a concessão fiscal para uma empresa gera certamente aumento de alíquota para outra, que não o recebeu.

A princípio, é importante ressaltar que, em diversos exercícios financeiros, o governo estadual apresentou suas contas ao TCE-RJ tendo como base valores empenhados e não liquidados ou pagos. O art. 58 da Lei 4.320/1964 define o empenho como apenas um ato que obriga a autoridade pagar; portanto, ele pode ser cancelado, ao contrário da liquidação, que só é realizada após a entrega do material ou serviço mediante nota fiscal.

Não é incomum que governos contabilizem despesas alheias e/ou questionáveis à MDE. Uma das principais, que inflam o percentual da MDE, é a dos inativos da educação. Isso porque há uma celeuma legal entre o silenciamento em relação a essa despesa no art. $70 \mathrm{e}$ 71 da LDB e a Lei federal 7.348/85, que a define como MDE. Em 2017, a despesa com inativos consumiu $\mathrm{R} \$ 3,5$ bilhões de reais da MDE da rede estadual de ensino do Rio de Janeiro (SOUZA, 2019). As despesas com a Fundação Carlos Chagas Filho de Amparo à Pesquisa do Estado do Rio de Janeiro (Faperj) e com a Fundação Centro Estadual de Estatística, Pesquisa e Formação de Servidores Públicos do Rio de Janeiro (Ceperj), com restos a pagar cancelados, entre outras, foram incluídas para fins do alcance do percentual mínimo e excluídas pela equipe técnica do TCE. Em 2019, as exclusões de despesas alheias à MDE chegaram a mais de $\mathrm{R} \$ 647$ milhões, o que refletiu no não cumprimento do percentual mínimo de impostos na MDE, que alcançou somente $24,4 \%$ da receita líquida de impostos, 
Os efeitos do Fundeb na rede estadual de ensino do Rio de Janeiro (2007-2020)

contrariando assim o determinado pelo artigo 212 da CRFB/88 (RIO DE JANEIRO; TCE-RJ, 2019).

O exposto acima alerta para o cuidado necessário ao analisar-se dados e valores oficiais tomando-os como verdadeiros. Não é incomum pesquisas científicas adotarem tais valores sem revelar suas determinações. Isso induz os leitores a uma farsa que em nada contribui para a análise da aplicação dos recursos públicos no ensino.

Em relação ao Fundeb estadual, o Gráfico II demonstra que os recursos recolhidos dos impostos e transferências e destinados ao Fundo quase sempre foram crescentes: em geral, cresceram $68 \%$, de 2007 a 2020. O mesmo ocorreu com o valor recebido pelo governo estadual, que representou $66 \%$ de crescimento no período de 2007 a 2020 . Enquanto as perdas de recursos representaram um aumento de $73 \%$ no mesmo período, a partir de 2013 superaram os recursos recebidos pelo governo estadual - tal perda se justifica pela diminuição das matrículas, na educação básica, sobretudo no ensino fundamental da rede estadual. O governo estadual atribui a queda de matrículas aos fatores demográficos, relacionados à dinâmica populacional humana. Contudo, segundo o Instituto Brasileiro de Geografia e Estatística (IBGE), através da Pesquisa Nacional por Amostra de Domicílios Contínua (PNAD-C), há 58 mil jovens na faixa etária de 15 a 17 anos fora da escola no estado do Rio de Janeiro (IBGE, 2015).

\section{Gráfico II - Recursos do Fundeb da rede estadual 2007 a 2020 - valores nominais (em bilhões)}

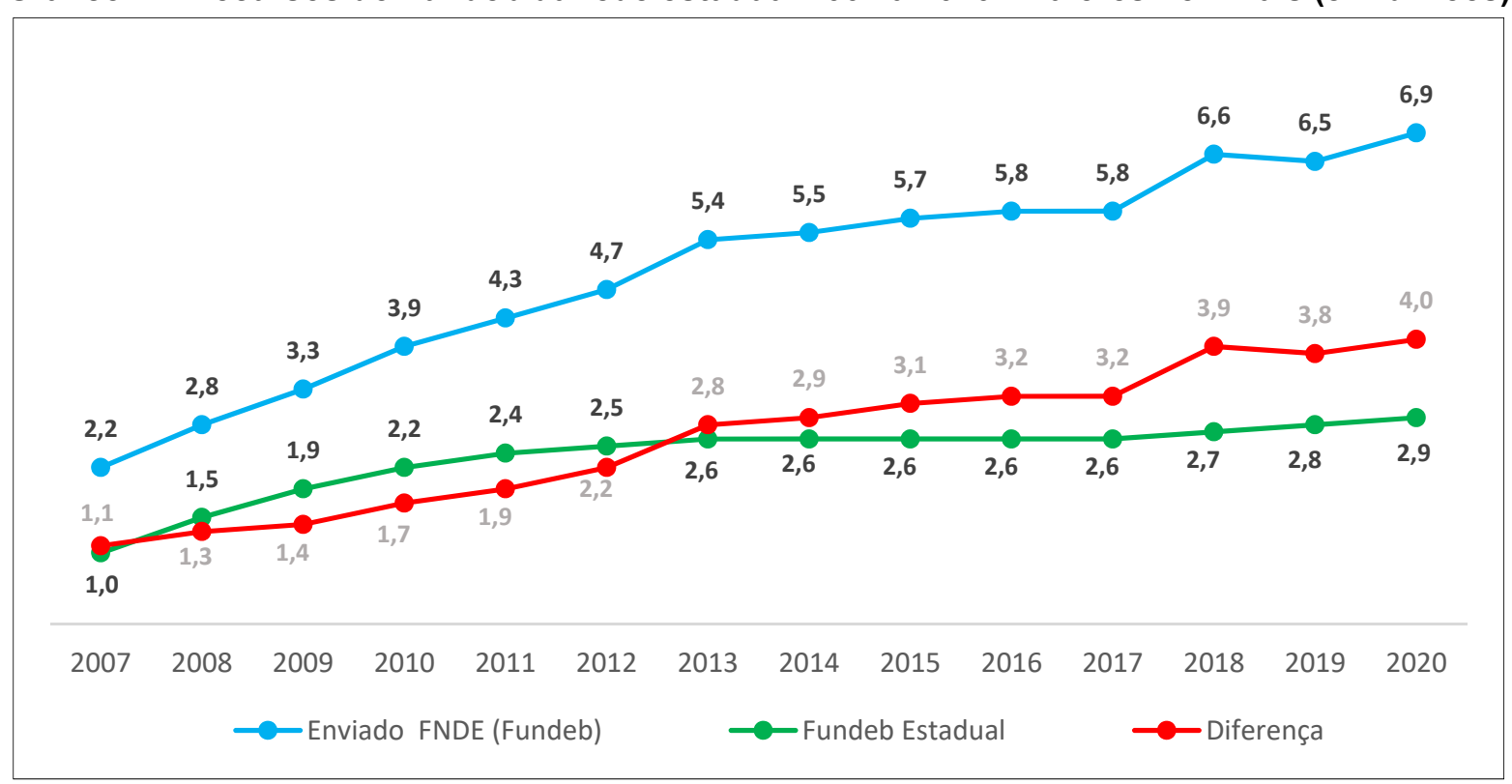

Fonte: Gráfico elaborado pelo autor com base nos dados de TCE-RJ, LOA 2020 e Siope/FNDE-MEC.

O estímulo da política de municipalização se intensificou com a Lei federal 5.692/1971. Segundo o parágrafo único do art. 58 , a progressiva passagem do ensino de $1^{\circ} \mathrm{grau}$ (o atual ensino fundamental) para os municípios seria realizada mais satisfatoriamente pela administração local. No estado do Rio de Janeiro, em 1978, implantou-se, nessa conjuntura, o Projeto de Coordenação e Assistência Técnica ao Ensino Municipal (Promunicípio), tendo como um dos objetivos a formalização de convênio de assistência financeira e técnica entre estado e municípios para a transferência de matrículas. 
Os efeitos do Fundeb na rede estadual de ensino do Rio de Janeiro (2007-2020)

Em 1987, no governo de Wellington Moreira Franco, a Resolução 1.411, da Secretaria de Educação (SEE/RJ), instituiu o Programa de Municipalização do Ensino de $1^{\circ}$ Grau do Estado do Rio de Janeiro (Promurj), com o intuito de formalizar convênio com as prefeituras para municipalizar escolas estaduais. O governo Marcello Alencar criou ainda mais duas políticas visando ao processo de municipalização das escolas estaduais, sobretudo dos Centros Integrados de Educação Pública (Cieps), implantados nos governos de Leonel Brizola (19831987/1991-1994).

A política educacional nos governos de Sérgio Cabral/Pezão (2007/2014-2014/2018) foi norteada pelo discurso de produtividade e eficiência, exigido pelas novas demandas da sociedade capitalista. Entre as políticas educacionais adotadas no governo, destacam-se: o Plano de Metas, o Sistema de Avaliação da Educação do Estado do Rio de Janeiro (Saerj), o Sistema de Avaliação Bimestral (Saerjinho), o Índice de Desenvolvimento da Educação do Estado do Rio de Janeiro (Iderj) e o Sistema de Bonificação por Resultados.

A equipe técnica do TCE-RJ, ao analisar as contas de 2007 a 2019 (governo Wilson Witzel), detectou ilegalidade e irregularidades tanto na contabilização das receitas como nas despesas do Fundeb. No que concerne às receitas, foi possível constatar que, em diversos exercícios financeiros, houve contabilização dos valores para a formação do Fundeb inferior ao valor devido: em 2018, essa ilegalidade resultou na não contabilização de quase $R \$ 1$ bilhão (RIO DE JANEIRO; TCE-RJ, 2018); e a dedução do FECP e do FAF antes da dedução dos percentuais para o Fundeb. Em relação às despesas, foram constatados gastos que não se enquadram como MDE, como, por exemplo, as pensões; a falta de abertura de créditos suplementares, para a realização de gastos com os recursos remanescentes do Fundeb relativos ao exercício anterior; e a falta de detalhamento das despesas. No que se refere ao acompanhamento e controle social em todos os relatórios do TCE-RJ, foi possível constatar a inoperância do CACS-Fundeb estadual refletida na ausência de assinatura da maioria dos conselheiros, sobretudo dos representantes de pais, alunos e sindicatos, no parecer anual que deve ser encaminhado ao Tribunal (RIO DE JANEIRO; TCE-RJ, 2007; 2008; 2009; 2010; $2011 ; 2012 ; 2013 ; 2014 ; 2015 ; 2016 ; 2017$; 2018; 2019 e 2020).

Em relação às matrículas estaduais, houve decréscimo em todas as etapas e modalidades da educação básica, comparando o ano de 2007 com 2019 (Gráfico III). Com base nas sinopses do censo educacional disponibilizadas pelo MEC, observa-se que, na educação infantil, as matrículas reduziram em $97,3 \%$ - cabe ressaltar que essa não é uma etapa prioritária do governo estadual. No ensino fundamental, a queda representou $66,8 \%$ no período de 2007 a 2019, embora essa seja uma etapa prioritária concorrente com os governos municipais. Mesmo no ensino médio, que é a área prioritária dos governos estaduais, as matrículas decresceram 17,3\%. O ensino profissionalizante e a Educação de Jovens e Adultos decresceram $19,1 \%$ e $52 \%$, respectivamente. 
Os efeitos do Fundeb na rede estadual de ensino do Rio de Janeiro (2007-2020)

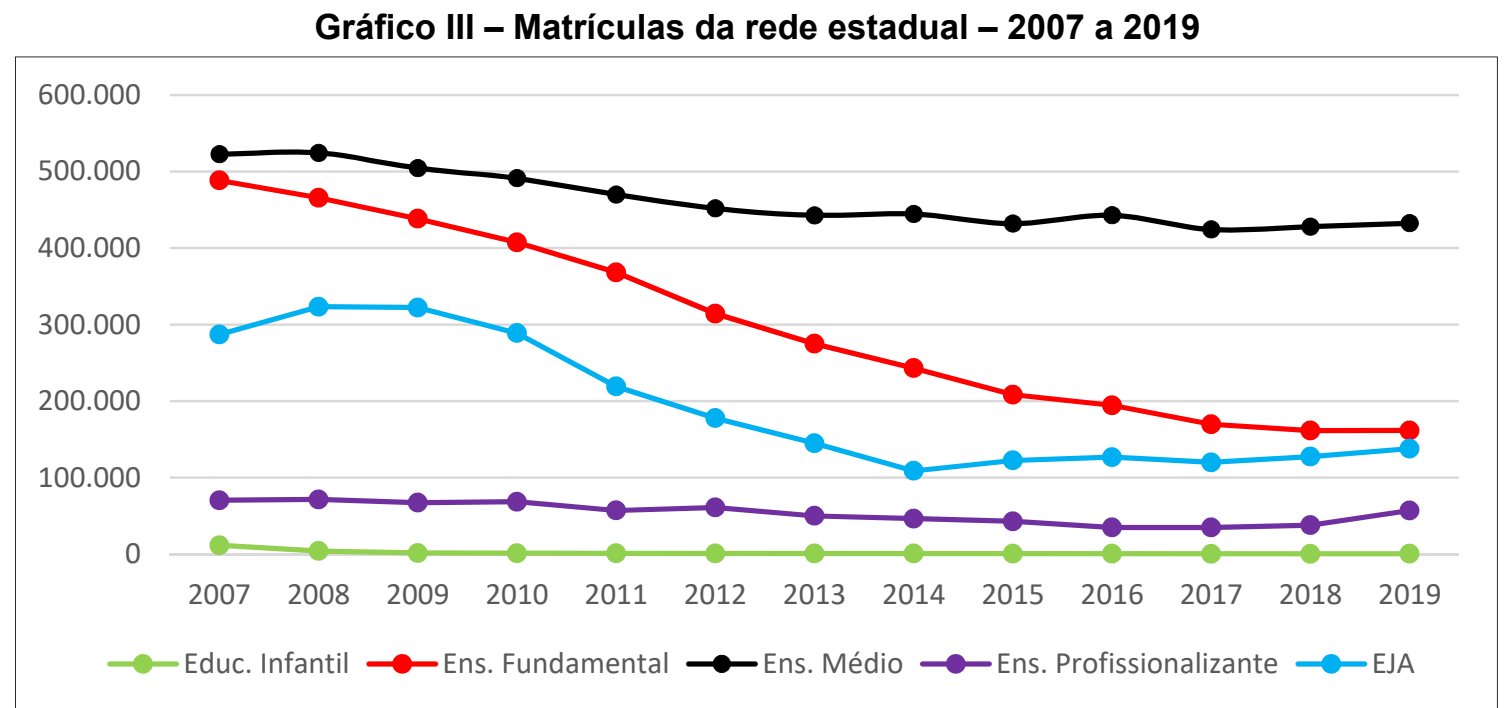

Fonte: Gráfico elaborado pelo autor com base nos dados de Sinopse Estatística da Educação Básica de 2007 a 2019/MEC.

Segundo Davies e Alcântara (2019), a rede estadual do Rio de Janeiro teve uma redução de 630.759 matrículas; por outro lado, as matrículas na rede privada cresceram em 257.111, de 2006 a 2017. Os autores apontam ainda que a Lei estadual 4.528/2005 (que estabelece as diretrizes para a organização do sistema de ensino do estado do Rio de Janeiro) e a Lei estadual 5.597/2009 (que criou o Plano Estadual de Educação) contribuíram para a redução das matrículas na educação infantil e no ensino fundamental, uma vez que textualmente induziram essas etapas à municipalização.

Uma questão intrigante acerca da queda de matrículas se refere à elevação da receita em MDE e do Fundeb. Na comparação dos Gráficos I, Il e III, é possível constatar que, embora as matrículas tenham caído significativamente, de 2007 a 2019, a receita com MDE e até mesmo com o Fundeb foi crescente no período. A receita com MDE se justifica, pois a RLIT foi crescente, já o aumento das receitas do Fundeb coloca uma questão à mesa, pois a distribuição do recurso se dá com base no número de matrículas da rede: então, se as matrículas diminuíram, como é possível que a receita com o Fundo tenha elevado?

As Tabelas I e II, logo abaixo, foram construídas a partir dos dados da estimativa de matrículas por etapas e modalidades, receita anual do Fundeb e valor anual por aluno da rede estadual do Rio de Janeiro disponibilizados pelo FNDE/MEC. O período analisado inicia em 2009, ano em que as matrículas passaram a contabilizar em sua totalidade. Na Tabela I é possível constatar a diminuição do número de matrículas da rede: em 2009, havia 1.189.781 alunos matriculados e, em 2020, o total caiu para 670.950 , ou seja, uma queda de $43,6 \%$; porém, a estimativa de receitas com o Fundo da rede estadual passou de $\mathrm{R} \$$ 1.797.420.693,43 para $\mathrm{R} \$ 2.913 .407 .964,73$ de 2009 para 2020 , ou seja, um crescimento de $38,3 \%$. A razão para tal crescimento se justifica pelo aumento do valor aluno/ano do Fundeb estadual, conforme se observa na Tabela II. 
Os efeitos do Fundeb na rede estadual de ensino do Rio de Janeiro (2007-2020)

Tabela I - Matrículas da educação básica, consideradas no Fundeb, estimativa da receita anual do fundo da rede estadual do Rio de Janeiro - valores nominais $(R \$ 1,00)$

\begin{tabular}{lrrr}
\hline \multicolumn{1}{c}{ ETAPAS/MODALIDADES } & $\mathbf{2 0 0 9}$ & $\mathbf{2 0 2 0}$ & Variação (\%) \\
\hline Séries Iniciais Urbanas & 75.394 & 1.331 & $-98,2$ \\
Séries Iniciais Rurais & 3.757 & 2 & $-99,9$ \\
Séries Finais Urbanas & 328.276 & 148.161 & $-54,9$ \\
Séries Finais Rurais & 14.137 & 7.465 & $-47,2$ \\
Tempo Integral & 38.681 & 1.437 & $-96,3$ \\
Ensino Médio Urbano & 472.745 & 365.334 & $-22,7$ \\
Ensino Médio Rural & 10.194 & 12.133 & 19,0 \\
Tempo Integral & 776 & 5.879 & 657,6 \\
Ens. Médio Integrado Educ. Prof. & 40.724 & 49.041 & 20,4 \\
Educação Especial & 4.238 & 3.762 & $-11,2$ \\
AEE & - & 544 & - \\
EJA - Avalição Processo & 197.101 & 75.658 & $-61,6$ \\
EJA Integrado Educ. Prof. & 515 & - & - \\
Educ. Indígena/Quilombola & 1.450 & 203 & $-86,0$ \\
Educação Especial Conveniada & 1.793 & - & $-98,2$ \\
\hline TOTAL DE MATRícULAS & $\mathbf{1 . 1 8 9 . 7 8 1}$ & $\mathbf{6 7 0 . 9 5 0}$ & $\mathbf{- 4 3 , 6}$ \\
\hline Valor Fundeb & $\mathbf{1 . 7 9 7 . 4 2 0 . 6 9 3 , 4 3}$ & $\mathbf{2 . 9 1 3 . 4 0 7 . 9 6 4 , 7 3}$ & $\mathbf{3 8 , 3}$ \\
\hline
\end{tabular}

Fonte: Tabela elaborada pelo autor com base nos dados de FNDE/MEC.

Mesmo com perda de $43,6 \%$ das matrículas, a rede estadual teve sua receita com o Fundeb aumentada em 38,3\%, de 2009 a 2020. A lógica de distribuição dos recursos do Fundeb permite que, mesmo com o encolhimento da sua rede, o estado consiga ter aumento de sua receita com o Fundo. Conforme a Tabela II, o valor anual de um aluno do ensino médio urbano (no qual está concentrado o maior número de matrículas estaduais) passou de $\mathrm{R} \$$ $1.651,27$ para $\mathrm{R} \$ 4.639,72$ de 2009 para 2020 , um crescimento de $66,6 \%$.

Estrategicamente, os gestores estaduais da educação optaram por diminuir as matrículas, sobretudo porque a medida vai ao encontro das políticas ultraliberais para as áreas sociais, pois, ao mesmo tempo que diminui a responsabilidade do Estado no direito à educação, enseja o crescimento do setor privado nessa área social. Outro elemento que, provavelmente, determinou a opção por reduzir as matrículas na educação básica tem relação com as avaliações em larga escala. À medida que diminui o universo de alunos que participam dos exames, há mais recursos para aplicar em uma rede encolhida e com isso conquistar maiores notas. Essa política teve resultados positivos nas avalições do Índice de Desenvolvimento da Educação Básica (Ideb) de 2011, 2013 e 2015, como se verá adiante. 
Os efeitos do Fundeb na rede estadual de ensino do Rio de Janeiro (2007-2020)

Tabela II - Valor anual por aluno estimado da rede estadual do Rio de Janeiro - valores nominais $(R \$ 1,00)$

\begin{tabular}{lrrc}
\hline \multicolumn{1}{c}{ ETAPAS/MODALIDADES } & $\mathbf{2 0 0 7}$ & $\mathbf{2 0 2 0}$ & Variação (\%) \\
\hline Séries Iniciais Urbanas & $1.241,23$ & $3.711,77$ & 66,6 \\
Séries Iniciais Rurais & $1.303,29$ & $4.268,54$ & 69,5 \\
Séries Finais Urbanas & $1.365,35$ & $4.082,95$ & 66,6 \\
Séries Finais Rurais & $1.427,41$ & $4.454,13$ & 68,0 \\
Tempo Integral & $1.551,53$ & $4.825,30$ & 67,8 \\
Ensino Médio Urbano & $1.489,47$ & $4.639,72$ & 67,9 \\
Ensino Médio Rural & $1.551,53$ & $4.825,30$ & 67,8 \\
Tempo Integral & $1.613,59$ & $4.825,30$ & 66,6 \\
Ens. Médio Integrado Educ. Prof. & $1.613,59$ & $4.825,30$ & 66,6 \\
Educação Especial & $1.489,47$ & $4.454,13$ & 66,6 \\
AEE & - & $4.454,13$ & - \\
EJA - Avalição Processo & 868,86 & $2.969,42$ & 70,7 \\
EJA Integrado Educ. Prof. & 868,86 & $4.454,13$ & 80,5 \\
Educ. Indígena/Quilombola & $1.489,47$ & $4.454,13$ & 66,6 \\
Educação Especial Conveniada & - & $4.454,13$ & - \\
\hline
\end{tabular}

Fonte: Tabela elaborada pelo autor com base nos dados de FNDE/MEC.

Desde meados de 1990, o Brasil consolidou a avaliação externa das escolas através do Sistema de Avaliação da Educação Básica (Saeb), com base em resultados da aprendizagem aferidos por instrumentos cognitivos e contextuais desenvolvidos pelo Instituto Nacional de Estudos e Pesquisas Educacionais Anísio Teixeira (Inep). Em 2000, o País passou a participar do Programme for International Student Assessment (Pisa) [Programa Internacional de Avaliação de Estudantes], realizado pela Organização para Cooperação e Desenvolvimento Econômico (OCDE).

Criado em 2007, o Ideb é o resultado do cálculo entre dados da aprovação escolar obtidos no Censo Escolar e das médias de desempenho nas avaliações do Saeb - para estados, Distrito Federal e para o País - e da Prova Brasil, para os municípios. A importância dada à avaliação externa e a cultura da avaliação refletiram na criação de avaliações estaduais e municipais com formato muito parecido ao do indicador nacional.

A gestão educacional ficou concentrada na obtenção de resultados. Como um dos efeitos disso, houve a responsabilização por resultados, que redundou nas políticas de bonificação aos profissionais da educação e às escolas que obtivessem os maiores avanços nas avaliações externas. Em 2008, o governo estadual criou o Saerj, com o objetivo de coletar informações sobre o desempenho escolar dos estudantes a fim de atender demandas de ensino e de aprendizagem no contexto escolar, além de articular o planejamento de medidas em todos os níveis do sistema de ensino (CAED, 2019). Após a insatisfação com os resultados do Ideb de 2009, Sérgio Cabral nomeou como secretário estadual de educação o economista Wilson Risolia, que ficou no cargo pelo maior período desde a década de 1990.

Ao afirmar em entrevista que "pensa a educação como um negócio", o secretário deixou explícito o caráter ultraliberal com o qual adotaria as políticas educacionais no estado. Nesse sentido, a busca desenfreada para alcançar melhores notas no Ideb marcou sua gestão. Com isso, o modo de produção capitalista foi reproduzido através das implementações de políticas de bonificações por resultados; do plano de metas; da reconfiguração do sistema de avaliação 
estadual através da criação do Iderj; da criação do Programa Saerjinho (avaliação bimestral para alunos dos $3^{\circ}$ e $5^{\circ}$ anos); do Programa de Avaliação Externa; da criação do currículo mínimo; do Projeto Autonomia, uma parceria milionária com a Fundação Roberto Marinho, cujo objetivo foi combater a reprovação e a evasão escolar na rede (mas que funcionou para isolar alunos com distorção idade-série, não passando pela avalição nacional, o que contribuiu, portanto, para a elevação do (deb); entre outras medidas.

Contudo, a insatisfação com os resultados das políticas adotadas nos governos Cabral para a educação, sobretudo por parte do Sindicato Estadual dos Profissionais da Educação (Sepe), mobilizou diversas greves e campanhas, culminando na conscientização crítica de parte da sociedade. Em 2015, em meio às ocupações das escolas estaduais pelos secundaristas, foi posto, entre os pontos de reivindicação, o fim do Saerj. No intuito de acabar com as ocupações, que duraram mais de 4 meses, o governo atendeu, entre outras reinvindicações, o fim do Sistema Saerj (SILVA, 2019). Em 2016, diante da crise política e fiscal que assolou o País, muitas unidades federadas implementaram políticas de austeridade fiscal, prejudicando diretamente as áreas sociais (ROSSI et al., 2019). No Rio de Janeiro, decretou-se calamidade pública em razão da crise financeira, consequentemente, os cortes nos recursos da educação fluminense comprometeram as políticas educacionais adotadas na rede estadual.

No que se refere ao ensino médio, a rede estadual ocupou em 2009 uma das piores notas do Ideb, empatando, no ranking nacional, em penúltimo lugar com Amapá, Rio Grande do Norte e Alagoas. Em 2011, ficou em $8^{\circ}$ lugar (de 13 notas), pois muitas redes estaduais empataram; na avaliação de 2015, ocupou o $5^{\circ}$ lugar; já em 2017, a nota do Ideb para o ensino médio caiu e ficou longe da meta projetada, ocupando a $8^{a}$ posição, de 14 colocações; já nas avaliações de 2011 e 2015, período em que as políticas gerencialistas foram intensamente implementadas na gestão Cabral/Risolia, houve um aumento da nota no ensino médio da rede estadual (Gráfico IV).

Gráfico IV - Ideb da rede estadual - 2007, 2009, 2011, 2015 e 2017

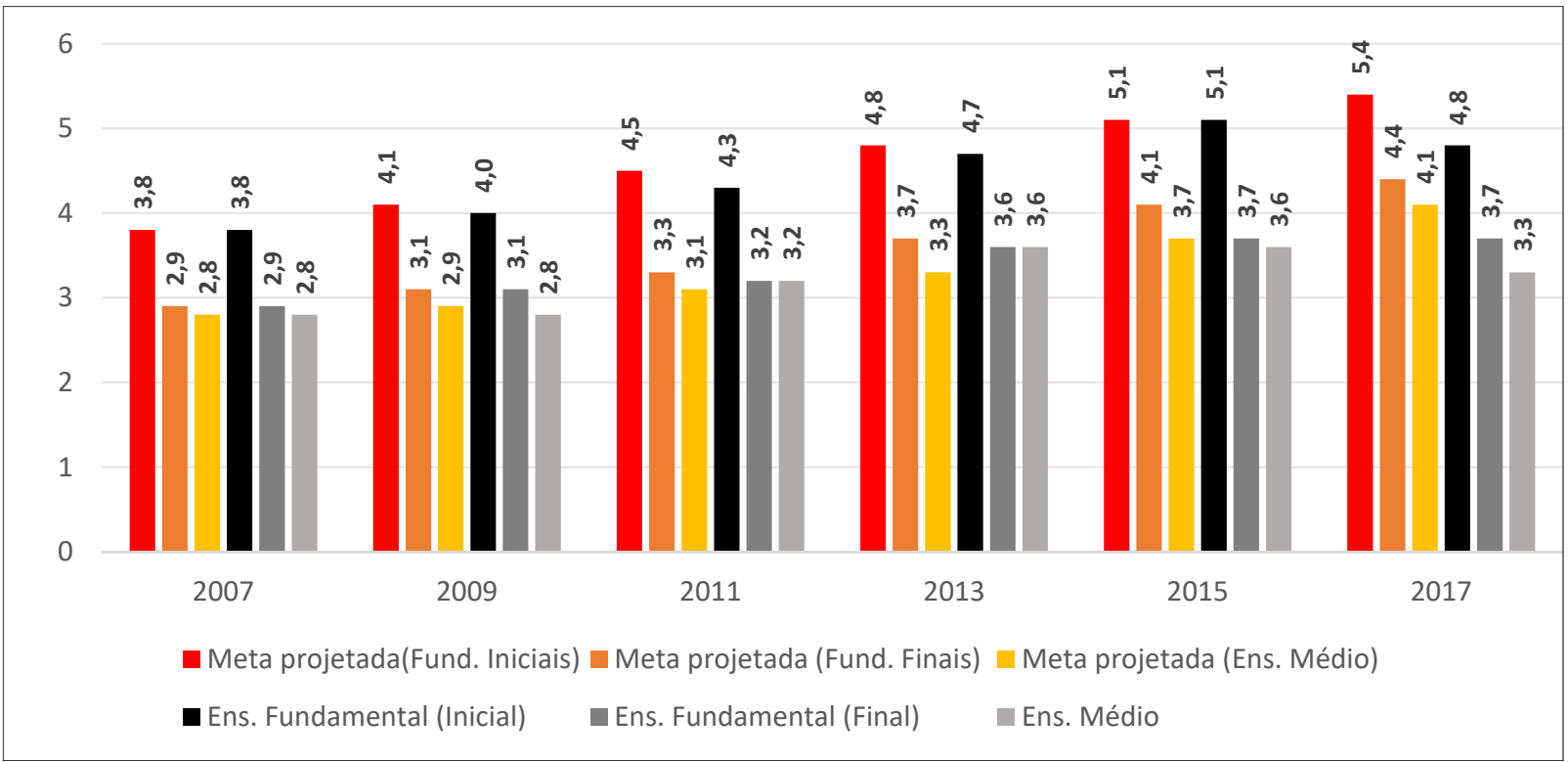

Fonte: Gráfico elaborado pelo autor com base nos dados de INEP/MEC. 
Os recursos do Fundeb da rede estadual foram majoritariamente destinados para pagar a remuneração dos profissionais do magistério. O total da receita com o Fundeb, de 2007 a 2019 , foi de $R \$ 30,2$ bilhões, dos quais $R \$ 27,3$ foram destinados para pagar os profissionais do magistério, o que não significou, contudo, uma melhoria no vencimento inicial destes (Gráfico V).

\section{Gráfico V - Aplicação dos recursos do Fundeb da rede estadual 2007 a 2019 - valores nominais (em bilhões)}

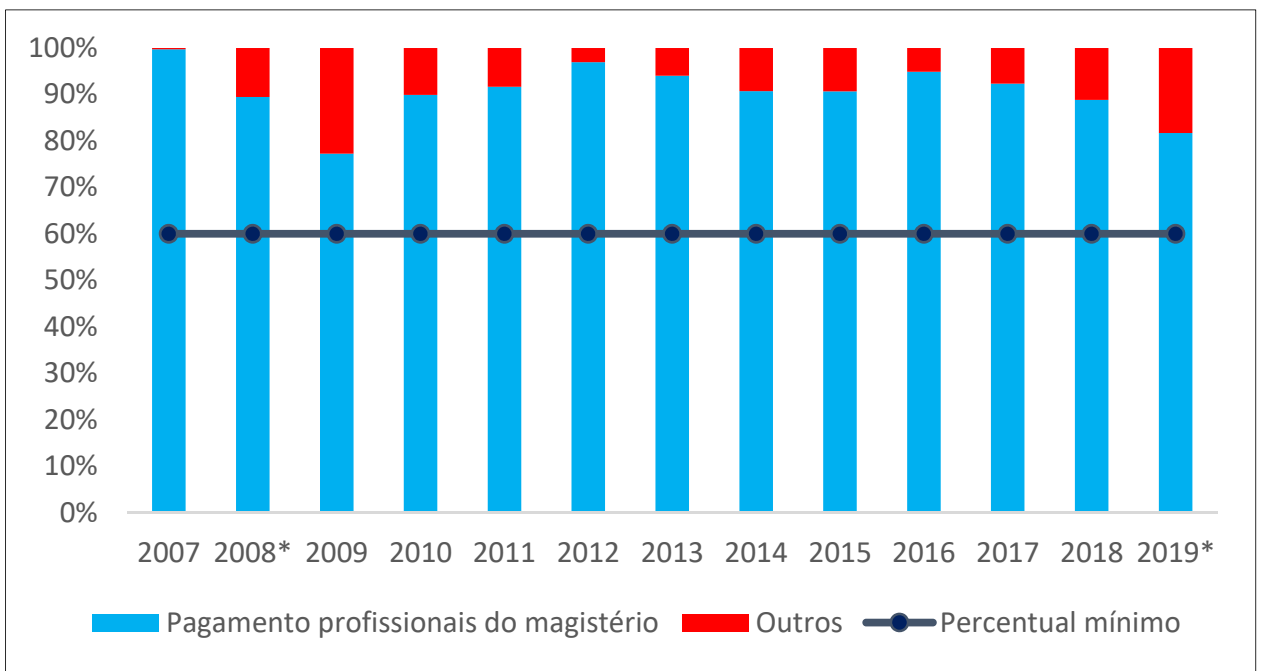

Fonte: Gráfico elaborado pelo autor com base nos dados de TCE-RJ e Siope/FNDE-MEC (para os dados de 2008 e 2019)

Conforme a Tabela III, é possível constatar que o reajuste do vencimento inicial dos docentes com jornadas de 16, 22 e 40 horas foi de $52,3 \%$ e, dos docentes de 30 horas, de $25,5 \%$, no período de 2007 a 2020, ficando abaixo do reajuste do salário mínimo nacional e do Piso Salarial Profissional Nacional (PSPN) aprovado, em 2008, pela Lei federal 11.738. Além disso, os reajustes foram minados pela inflação, que totalizou 74,4\%, de 2007 a 2020. Com isso, os docentes com carga horária de 16, 22 e 40 horas sofreram perda salarial de $22,1 \%$, enquanto os de 30 horas tiveram perda de $48,9 \%$. Ademais, os docentes sofrem com o congelamento dos enquadramentos pelo Plano de Carreira (Lei estadual 1.614/1990), o que aprofundou ainda mais sua desvalorização.

Tabela III - Vencimento inicial dos docentes da rede estadual, salário mínimo, PSPN e inflação - valores nominais $(R \$ 1,00)$

\begin{tabular}{|c|c|c|c|c|c|}
\hline \multicolumn{2}{|c|}{ EXERCÍCIO FINANCEIRO } & 2007 & 2011* & 2020 & VARIAÇÃO (\%) \\
\hline \multirow{5}{*}{$\begin{array}{l}\text { VENCIMENTO } \\
\text { INICIAL (Vi) }\end{array}$} & Professor Docente I 16h & 562,26 & & $1.179,35$ & 52,3 \\
\hline & Professor Docente II 22h & 448,24 & & 940,00 & 52,3 \\
\hline & Professor Docente I 30h* & - & $1.646,08$ & $2.211,25$ & 25,5 \\
\hline & Professor Docente I 40h & $1.405,68$ & & $2.948,33$ & 52,3 \\
\hline & Professor Docente II 40h & 896,48 & & $1.880,32$ & 52,3 \\
\hline \multicolumn{2}{|c|}{ SALÁRIO MÍNIMO } & 380,00 & & $1.039,00$ & 63,4 \\
\hline \multicolumn{2}{|r|}{ PSPN } & 950,00 & & $2.886,24$ & 67,1 \\
\hline \multicolumn{3}{|c|}{ INPC (2007-2020) } & \multicolumn{3}{|c|}{74,4} \\
\hline
\end{tabular}

${ }^{*} \mathrm{O}$ cargo docente com carga horária de 30 horas foi criado em 2011.

Fontes: Tabela elaborada pelo autor com base nos dados de IBGE, Ministério da Economia e Souza (2016). 
Os efeitos do Fundeb na rede estadual de ensino do Rio de Janeiro (2007-2020)

\section{Aspectos conclusivos}

A crise estrutural capitalista tem buscado medidas para sustentar o desenvolvimento capitalista, uma delas é a sua expansão através da captação de recursos públicos da educação pública. O valor do mercado educacional mundial foi de $\$ 4,9$ trilhões (USD) em 2015. No Brasil, o número de empresas com atividades ligadas à educação cresceu, em 2019, chegando a quase R\$ 1,8 milhão, uma alta de 37,5\% se comparado com 2018 (IBGE, 2020). Para Rikowski (2017, p. 398): "Nessas circunstâncias, a tomada de controle sobre a educação por parte das empresas não parece surpreendente, o que estimula a sua privatização". A capitalização da educação pública é uma das formas encontradas pelo sistema capitalista para transformar a receita do Estado em lucro privado. Não obstante, o Fundeb é uma política que repassa recursos para instituições privadas de ensino (comunitárias, confessionais ou filantrópicas sem fins lucrativos, conveniadas com o poder público).

Por fim, é importante ressaltar que, ao comparar o Fundef com o Fundeb, fica a impressão da superioridade deste em relação àquele, sobretudo porque o Fundef teve mais problemas que o Fundeb; porém, trata-se de duas políticas com graves problemas para solucionar os desafios da educação brasileira. Conceber o Fundeb como a redenção para os problemas da universalização e da qualidade da educação básica seria o mesmo que "tampar o sol com uma peneira", haja vista que os principais entraves do financiamento da educação decorrem das políticas neoliberais e neoconservadoras. Estas refletem o progressivo desinvestimento nas áreas sociais e a consequente capitalização das sociedades de economia capitalista, processo que, por sua vez, influencia diretamente no desenho institucional das políticas sociais, hegemonizando os efeitos de tais políticas, sobretudo em países de economia dependente, como o Brasil.

\section{Referências}

ARAUJO, Gilda Cardoso de. Estado, política educacional e direito à educação no Brasil: "o problema maior é o de estudar". Educar em Revista, Curitiba, n. 39, p. 279-292, 2011.

AZEVEDO, Fernando de. A reconstrução educacional no Brasil. Ao povo e ao governo. $O$ manifesto dos pioneiros da educação nova. São Paulo: Ed. Nacional, 1932.

BRASIL. Decreto n 21.335/1932. Institui a Taxa de Educação e Saúde, de duzentos reis, sobre todos os documentos sujeitos a selo federal, estadual ou municipal, criando o fundo especial respectivo. Diário Oficial, Rio de Janeiro, 1932. Disponível em: http://legislacao. planalto.gov.br/legisla/legislacao.nsf/Viwldentificacao/dec\%2021.335-1932?OpenDocument. Acesso em: 21 mar. 2020.

BRASIL. Constituição da República dos Estados Unidos do Brasil (16 de Julho de 1934). Diário Oficial, Rio de Janeiro, 1934. Disponível em: http://www.planalto.gov.br/ccivil_03/ constituicao/constituicao34.htm. Acesso em: 21 mar. 2020.

BRASIL. Decreto-Lei $n^{\circ} 4.958$, de 14 de novembro de 1942. Institui o Fundo Nacional do Ensino Primário e dispõe sobre o Convênio Nacional de Ensino Primário. Diário Oficial, Rio de Janeiro, 1942. Disponível em: https://www2.camara.leg.br/legin/fed/declei/19401949/decreto-lei-4958-14-novembro-1942-414976-norma-pe.html. Acesso em: 21 mar. 2020. 
Os efeitos do Fundeb na rede estadual de ensino do Rio de Janeiro (2007-2020)

BRASIL. Lei $n^{\circ}$ 4.024, de 20 de dezembro de 1961. Fixa as diretrizes e bases da educação nacional. Lei de Diretrizes e Bases da Educação-LDB. Diário Oficial da União, Brasília, DF, 1961. Disponível em: http://wwwp.fc.unesp.br/ lizanata/LDB\%204024-61.pdf. Acesso em: 14 set. 2019.

BRASIL. Lei $n^{\circ} 4.320 / 64$, de 17 de março de 1964. Estatui normas gerais de direito financeiro para a elaboração e controle dos orçamentos e balanços da União, Estados, Municípios e do Distrito Federal. Diário Oficial da República Federativa do Brasil, Brasília, DF, de 23 de março de 1964. Disponível em: http://www.planalto.gov.br/ ccivil_03/Leis/L4320.htm. Acesso em: 8 nov. 2010.

BRASIL. Lei $n^{\circ}$ 5.692, de 11 de agosto de 1971. Fixa diretrizes e bases para o ensino de $1^{\circ} \mathrm{e}$ $2^{\circ}$ graus, e dá outras providências. Lei de Diretrizes e Bases da Educação Nacional. Diário Oficial da União, Brasília, DF, 1971. Disponível em: http://www.educacao.salvador.ba.gov.br/ site/documentos. Acesso em: 01 dez. 2019.

BRASIL. Lei $n^{\circ} 7.348$, de 24 de julho de 1985. Dispõe sobre a execução do $\S 4^{\circ}$ do art. 176 da Constituição Federal, e dá outras providências. Diário Oficial da União, Brasília, DF, 24 jul. 1985. Disponível em: http://www.planalto.gov.br/ccivil_03/LEIS/1980-1988/L7348.htm. Acesso em: 8 abr. 2019.

BRASIL. Constituição da República Federativa do Brasil de 1988. Diário Oficial da União, Brasília/DF, 1988. Disponível em: http://www.planalto.gov.br/ccivil_03/constituicao/constitui cao34.htm. Acesso em: 21 mar. 2020.

BRASIL. Lei $n^{\circ}$ 9.394, de 20 de dezembro de 1996. Estabelece as diretrizes e bases da educação nacional. Diário Oficial da União, Brasília, DF, 23 dez. 1996a.

BRASIL. Lei no 9.424, de 24 de dezembro de 1996. Regulamenta o Fundo de Manutenção e Desenvolvimento do Ensino Fundamental e de Valorização dos Profissionais do Magistério Fundef. Diário Oficial da União, Brasília, DF, 26 dez. 1996b.

BRASIL. Emenda Constitucional n. 14, de 12 de setembro de 1996. Modifica os arts. 34, 208, 211 e 212 da Constituição Federal e dá nova redação ao art. 60 do Ato das Disposições Constitucionais Transitórias. Diário Oficial da União, Brasília, DF, 13 set. 1996c. Disponível em: http://www.planalto.gov.br/ccivil_03/constituicao/emendas/emc/emc14.htm. Acesso em: 8 jan. 2016.

BRASIL. Câmara dos Deputados. Proposta de Emenda Constitucional do Fundeb (PEC 415). Brasília/DF, 2005. Disponível em: https://www.camara.leg.br/proposicoesWeb/fichadet ramitacao?idProposicao=290585. Acesso em: 17 mar. 2020.

BRASIL. Emenda Constitucional $n^{\circ} 53$, de 19 de dezembro de 2006. Dá nova redação aos arts. $7^{\circ}, 23,30,206,208,211$ e 212 da Constituição Federal e ao art. 60 do Ato das Disposições Constitucionais Transitórias. Diário Oficial da União, Brasília/DF, 2006. Disponível em: http://www.planalto.gov.br. Acesso em: 21 mar. 2020.

BRASIL. Lei $n^{\circ} 11.494$, de 20 de junho de 2007. Regulamenta o Fundo de Manutenção e Desenvolvimento da Educação Básica e de Valorização dos Profissionais da Educação Fundeb. Diário Oficial da União, Brasília, DF, 21 jun. 2007. 
BRASIL. Lei n. 11.738, de 16 de julho de 2008. Regulamenta a alínea "e" do inciso III do caput do art. 60 do Ato das Disposições Constitucionais Transitórias, para instituir o piso salarial profissional nacional para os profissionais do magistério público da educação básica. Diário Oficial da União, Brasília, 2008. Disponível em: http://planalto.gov.br/ccivil_03/_Ato20072010/2008/Lei/L11738.htm. Acesso em: 29 mar. 2020.

BRASIL. Emenda Constitucional $n^{\circ} 59$, de 11 de novembro de 2009. Acrescenta $\S 3^{\circ}$ ao art. 76 do Ato das Disposições Constitucionais Transitórias para reduzir, anualmente, a partir do exercício de 2009, o percentual da Desvinculação das Receitas da União incidente sobre os recursos destinados à manutenção e desenvolvimento do ensino de que trata o art. 212 da Constituição Federal, dá nova redação aos incisos I e VII do art. 208, de forma a prever a obrigatoriedade do ensino de quatro a dezessete anos e ampliar a abrangência dos programas suplementares para todas as etapas da educação básica, e dá nova redação ao $\S$ $4^{\circ}$ do art. 211 e ao $\S 3^{\circ}$ do art. 212 e ao caput do art. 214, com a inserção neste dispositivo de inciso VI. Diário Oficial da União, Brasília, 12 nov. 2009.

BRASIL. MEC. INEP. Sinopses estatísticas do Censo da Educação Básica: 2007 a 2019. Brasília: MEC, 2019. Disponível em: http://www.inep.gov.br. Acesso em: 25 jan. 2020.

CAED. UFJF. Centro de Políticas Públicas e avaliação da Educação da Universidade Federal de Juiz de Fora. Apresentação do Sistema de Avaliação da Educação do Estado do Rio de Janeiro (Saerj). Juiz de Fora, 2020. Disponível em: http://www.ava liacaoexternasaerj.caedufjf.net/. Acesso em: 14 maio 2020.

CALEGARI, Elizangela Borges da Silva et al. O controle social na administração pública municipal: responsabilidades e desafios do conselho do Fundeb. Constituição \& Justiça: Estudos e Reflexões, Orleans/SC, v. 1, n. 1, 2017.

DAVIES, Nicholas. O financiamento da educação: breve histórico da legislação e seus percalços. Revista Pesquisa e Debate em Educação, Juiz de Fora, v. 9, n. 2, 2019.

DAVIES, Nicholas; ALCÂNTARA, Alzira Batalha. Descompasso na educação básica no Estado do Rio de Janeiro: receitas dos governos crescem, porém, matrículas públicas caem. Revista Educação e Cultura Contemporânea, Rio de Janeiro, v. 16, n. 45, p. 31-54, 2019.

IBGE. Pesquisa Nacional por Amostra de Domicílios Contínua. Educação. Rio de Janeiro, 2015. Disponível em: https://www.ibge.gov.br/. Acesso em: 19 mar. 2020.

IBGE. Cadastro Central de Empresas - Cempre. Rio de Janeiro, 2020. Disponível em: https://www.ibge.gov.br/. Acesso em: 19 mar. 2020.

LEHER, Roberto. Um novo senhor da educação? A política educacional do Banco Mundial para a periferia do capitalismo. Outubro, São Paulo, v. 1, n. 3, p. 19-30, 1999.

NUNES, Alynne Nayara Ferreira. Financiamento da educação básica no Brasil: uma análise dos arranjos jurídicos adotados ao longo do período republicano. Revista Digital de Direito Administrativo, Ribeirão Preto, v. 4, n. 1, p. 32-58, 2017.

PINTO, José Marcelino Rezende. Ensino médio. In: OLIVEIRA, Romualdo Portela; ADRIÃO, Theresa. Organização do ensino no Brasil: níveis e modalidades na LDB e na Constituição Federal. São Paulo: Xamã, 2002. p. 51-76. 
Os efeitos do Fundeb na rede estadual de ensino do Rio de Janeiro (2007-2020)

RIKOWSKI, Glenn. Privatização em educação e formas de mercadoria. Retratos da Escola, Brasília-DF, v. 11, n. 21, p. 393-414, 2018.

RIO DE JANEIRO (Estado). Secretaria de Estado de Educação. Resolução no 1411, de 03 de dezembro de 1987. Instituiu o PROMURJ. Diário oficial do Estado, Rio de Janeiro, 1987. Disponível em: http://silep.fazenda.rj.gov.br/. Acesso em: 05 jan. 2020.

RIO DE JANEIRO (Estado). Secretaria de Estado de Educação. Lei n 1.614, de 24 de janeiro de 1990. Rio de Janeiro, 1990. Dispõe sobre o plano de carreira do magistério público estadual e dá outras providências. Diário oficial do Estado, Rio de Janeiro, 1990. Disponível em: http://silep.fazenda.rj.gov.br/. Acesso em: 05 fev. 2020.

RIO DE JANEIRO (Estado). Secretaria de Estado de Educação. Lei $n^{\circ} 5.597$, de 18 de dezembro de 2009. Institui o Plano Estadual de Educação - PEE/RJ, e dá outras providências. Diário oficial do Estado, Rio de Janeiro, 2009. Disponível em: http://silep.fazenda.rj.gov.br/. Acesso em: 05 fev. 2020.

RIO DE JANEIRO (Estado). Tribunal de Contas do Estado do Rio de Janeiro. Contas de Gestão do Governador - Exercício de 2007. Rio de Janeiro: TCE, 2007. Disponível em: http://www.tce.rj.gov.br. Acesso em: 29 mar. 2020.

RIO DE JANEIRO (Estado). Tribunal de Contas do Estado do Rio de Janeiro. Contas de Gestão do Governador - Exercício de 2008. Rio de Janeiro: TCE, 2008. Disponível em: http://www.tce.rj.gov.br. Acesso em: 29 mar. 2020.

RIO DE JANEIRO (Estado). Tribunal de Contas do Estado do Rio de Janeiro. Contas de Gestão do Governador - Exercício de 2009. Rio de Janeiro: TCE, 2009. Disponível em: http://www.tce.rj.gov.br. Acesso em: 29 mar. 2020.

RIO DE JANEIRO (Estado). Tribunal de Contas do Estado do Rio de Janeiro. Contas de Gestão do Governador - Exercício de 2010. Rio de Janeiro: TCE, 2010. Disponível em: http://www.tce.rj.gov.br. Acesso em: 29 mar. 2020.

RIO DE JANEIRO (Estado). Tribunal de Contas do Estado do Rio de Janeiro. Contas de Gestão do Governador - Exercício de 2011. Rio de Janeiro: TCE, 2011. Disponível em: http://www.tce.rj.gov.br. Acesso em: 29 mar. 2020.

RIO DE JANEIRO (Estado). Tribunal de Contas do Estado do Rio de Janeiro. Contas de Gestão do Governador - Exercício de 2012. Rio de Janeiro: TCE, 2012. Disponível em: http://www.tce.rj.gov.br. Acesso em: 29 mar. 2020.

RIO DE JANEIRO (Estado). Tribunal de Contas do Estado do Rio de Janeiro. Contas de Gestão do Governador - Exercício de 2013. Rio de Janeiro: TCE, 2013. Disponível em: http://www.tce.rj.gov.br. Acesso em: 29 mar. 2020.

RIO DE JANEIRO (Estado). Tribunal de Contas do Estado do Rio de Janeiro. Contas de Gestão do Governador - Exercício de 2014. Rio de Janeiro: TCE, 2014. Disponível em: http://www.tce.rj.gov.br. Acesso em: 29 mar. 2020.

RIO DE JANEIRO (Estado). Tribunal de Contas do Estado do Rio de Janeiro. Contas de Gestão do Governador - Exercício de 2015. Rio de Janeiro: TCE, 2015. Disponível em: http://www.tce.rj.gov.br. Acesso em: 29 mar. 2020. 
Os efeitos do Fundeb na rede estadual de ensino do Rio de Janeiro (2007-2020)

RIO DE JANEIRO (Estado). Tribunal de Contas do Estado do Rio de Janeiro. Contas de Gestão do Governador - Exercício de 2016. Rio de Janeiro: TCE, 2016. Disponível em: http://www.tce.rj.gov.br. Acesso em: 29 mar. 2020.

RIO DE JANEIRO (Estado). Tribunal de Contas do Estado do Rio de Janeiro. Contas de Gestão do Governador - Exercício de 2017. Rio de Janeiro: TCE, 2017. Disponível em: http://www.tce.rj.gov.br. Acesso em: 29 mar. 2020.

RIO DE JANEIRO (Estado). Tribunal de Contas do Estado do Rio de Janeiro. Contas de Gestão do Governador - Exercício de 2018. Rio de Janeiro: TCE, 2018. Disponível em: http://www.tce.rj.gov.br. Acesso em: 29 mar. 2020.

RIO DE JANEIRO (Estado). Tribunal de Contas do Estado do Rio de Janeiro. Contas de Gestão do Governador - Exercício de 2019. Rio de Janeiro: TCE, 2019. Disponível em: http://www.tce.rj.gov.br. Acesso em: 29 mar. 2020.

ROSSI, Pedro et al. Austeridade fiscal e o financiamento da educação no Brasil. Educação \& Sociedade, Campinas, v. 40, p. 01-20, 2019.

SENA, Paulo. A legislação do Fundeb. Cadernos de pesquisa, São Paulo, v. 38, n. 134, p. 319-340, 2008.

SILVA, Graciella Fabrício da. As ocupações de escolas da rede estadual do Rio de Janeiro (2016). Revista Despierta, Paraná, v. 6, n. 06, p. 135-162, 2019.

SOUZA, Fábio Araujo de. A remuneração dos professores da rede pública do estado do Rio de Janeiro (1995-2014). 2016. 306f. Tese (Doutorado em Educação) - Faculdade de Educação, Universidade de São Paulo, 2016.

SOUZA, Fábio Araujo de. Inativos da educação: despesa da educação? Revista Brasileira de Política e Administração da Educação, Goiânia, v. 35, n. 3, p. 1018-1051, 2019.

Fábio Araujo de Souza é professor adjunto da Faculdade de Educação da Universidade Federal do Rio de Janeiro (UFRJ) e docente do Programa de Pós-Graduação em Educação da UFRJ. Pós-doutor em educação pela Universidade Federal de Goiás (UFG). Doutor em educação pela Universidade de São Paulo (USP). Mestre em educação, cultura e comunicação nas periferias urbanas pela Universidade do Estado do Rio de Janeiro (UERJ). Pedagogo pela UERJ.

ORCID: http://orcid.org/0000-0001-9526-3302

E-mail:f.asouza@yahoo.com.br 


\section{Editores do volume 11}

Márcia Aparecida Jacomini - Universidade Federal de São Paulo, Brasil

José Marcelino de Rezende Pinto - Universidade de São Paulo, Brasil

\section{Comitê Editorial}

Nalú Farenzena - Universidade Federal do Rio Grande do Sul, Brasil

Juca Gil - Universidade Federal do Rio Grande do Sul, Brasil

Theresa Adrião - Universidade Estadual de Campinas, Brasil

Ângelo Ricardo de Souza - Universidade Federal do Paraná, Brasil

\section{Conselho Editorial}

\section{Alejandro Morduchowicz}

Universidad Pedagógica, Provincia de Buenos Aires, Argentina

Andréa Barbosa Gouveia

Universidade Federal do Paraná, Brasil

Fernanda Saforcada

Universidade de Buenos Aires, Argentina

Jacques Velloso

Universidade de Brasília, Brasil

João Monlevade

Senado Federal, Brasil

Jorge Abrahão de Castro

Instituto de Pesquisa Econômica Aplicada / IPEA, Brasil

Lisete Regina Gomes Arelaro

Universidade de São Paulo, Brasil

Luis Carlos Sales

Universidade Federal do Piauí, Brasil

Luiz de Sousa Junior

Universidade Federal da Paraíba, Brasil

Luiz Fernandes Dourado

Universidade Federal de Goiás, Brasil

Magna França

Universidade Federal do Rio Grande do Norte, Brasil

Marcos Edgar Bassi

Universidade Federal de Santa Catarina, Brasil

Maria Angélica Pedra Minhoto

Universidade Federal de São Paulo, Brasil

Maria Beatriz Luce

Universidade Federal do Rio Grande do Sul, Brasil

Maria Dilnéia Espíndola Fernandes

Universidade Federal de Mato Grosso do Sul, Brasil

Nelson Cardoso do Amaral

Universidade Federal de Goiás, Brasil

Nicholas Davies

Universidade Federal Fluminense, Brasil

Robert E. Verhine

Universidade Federal da Bahia, Brasil

Romualdo Portela de Oliveira

Universidade de São Paulo, Brasil

Rosana Gemaque Rolim

Universidade Federal do Pará, Brasil

Rubens Barbosa de Camargo

Universidade de São Paulo, Brasil

Theresa Adrião

Universidade Estadual de Campinas, Brasil

Tristan McCowan

University of London, Reino Unido

Vera Jacob

Universidade Federal do Pará, Brasil

Vera Peroni

Universidade Federal do Rio Grande do Sul, Brasil

Vitor Henrique Paro

Universidade de São Paulo, Brasil

\section{Equipe editorial}

Apoio ao Comitê Editorial: Caio Cabral da Silva

Diagramação, Revisão de português e normalização: Edson Leonel de Oliveira

Revisão de inglês: Sabrina Ferreira

Fineduca - Revista de Financiamento da Educação

Associação Nacional de Pesquisa em

Financiamento da Educação

e-mail: revista.fineduca@gmail.com | site: http://seer.ufrgs.br/fineduca 